\title{
Analisis Bilangan Richardson (Ri) untuk Stabilitas Atmosfer Iklim Mikro pada Maret 2021 di Konawe Selatan
}

\section{Analysis of Richardson Number (Ri) for Atmospheric Micro-Climate Stability on March 2021 in South Konawe}

\author{
Hendri Satria WD ${ }^{\mathbf{1}}$, Dewi Tamara Qothrunada ${ }^{2}$, Jefri Abednego Mondong ${ }^{3}$ \\ ${ }^{1,3}$ Pusat Jaringan Komunikasi, Badan Meteorologi Klimatologi dan Geofisika \\ ${ }^{2}$ Stasiun Klimatologi Konawe Selatan
}

\begin{tabular}{l} 
ARTICLE INFO \\
Article history: \\
DOI: \\
10.30595/pspfs.v2i.171 \\
Submitted: \\
July 29, 2021 \\
Accepted: \\
Sept 10, 2021 \\
Published: \\
Nov 10, 2021 \\
\hline Keywords: \\
Microclimate, Atmospheric \\
Stability, South Konawe, \\
Convection
\end{tabular}

\begin{abstract}
A microclimate is a complex of environmental variables that affect plants, including temperature, radiation, humidity, and wind. One of the additional atmospheric parameters that can be relevant in microclimate studies is the condition of atmospheric stability. The Richardson number derived from the temperature gradient and wind speed can determine the inversion interval in the atmosphere. The research was conducted at the Konawe Selatan Climatology Station to describe the condition of atmospheric stability and the convection process by calculating dynamic stability based on wind and temperature data at the level of 2 meters, 4 meters, and 7 meters in March 2021 from automatic tools. Based on observations in Condition 1, the atmosphere was seen in the morning dominated by neutral conditions, unstable in the afternoon, and stable in the afternoon. In condition 2 the atmosphere on a not rainy day and a rainy day in the morning was dominated by neutral conditions, free convection during the day, and forced convection at night. Free convection illustrated that the wind in the observation area was still dominated by monsoons and was still entering the rainy season. Also, forced convection illustrated that there was orographic rain; this was supported by the topography of the observation area, which was close to the hills and the Boroboro Mountains.
\end{abstract}

\section{This work is licensed under a Creative Commons Attribution 4.0} International License.

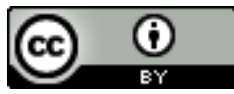

\section{Corresponding Author:}

Hendri Satria WD

Pusat Jaringan Komunikasi, Badan Meteorologi Klimatologi dan Geofisika

Email: hendrisatriawd@bmkg.go.id

\section{PENDAHULUAN}

Iklim mikro adalah kompleks variabel lingkungan, termasuk suhu, radiasi, kelembaban, dan angin, yang mengenai tanaman. Perubahan pada salah satu faktor ini menyebabkan perubahan pada faktor lainnya, dan perubahan ini dihasilkan dari pertukaran gaya, momentum, energi, atau massa. Dua jenis unsur penting adalah unsur radiasi, di mana energi ditransfer melalui getaran elektromagnetik, dan unsur difusif, di mana panas, uap air, dan $\mathrm{CO} 2$ dipertukarkan melintasi lapisan batas tanaman. Insiden fluks radiasi pada tanaman digabungkan dengan suhu tanaman dengan absorptivitasnya. Jika absorptivitas daun tinggi, maka suhu daun berhubungan erat dengan radiasi datang, dan sebaliknya. Unsur difusi melintasi lapisan batas dapat dilihat sebagai analog dari rangkaian listrik di mana energi dalam bentuk muatan bergerak dari potensial tinggi ke rendah (diukur sebagai tegangan) pada laju (arus) yang berbanding terbalik dengan resistensi. Produktivitas tanaman pada akhirnya 
tergantung pada pengaruh iklim mikro pada proses tanaman, seperti fotosintesis, respirasi, transpirasi, dan translokasi (Jones, 1985).

Seperti halnya klimatologi, Iklim mikro merupakan salah satu ilmu lingkungan. Menurut Thomp (1980) iklim mikro berhubungan dengan tanaman di atas wilayah atau luasan yang khas, sedang iklim mikro menggambarkan kondisi iklim lingkungan sekitar yang berhubungan langsung dengan organisme hidup, baik dekat permukaan bumi maupun pada lingkungan yang terbatas, misal ruangan, pabrik, dan rumah kaca. Menurut Geiger (1959), Iklim mikro adalah iklim di dekat permukaan tanah yaitu iklim tempat sebagian makhluk hidup berada. Geiger memperkirakan skala mikro kajian iklim mikro secara vertikal sampai dengan ketinggian $1,5-2$ meter.

Adapun faktor eksternal yang berpengaruh terhadap iklim mikro terdiri atas aktivitas manusia, tanaman dan jenis tanah. Ketiga faktor ini selanjutnya akan memicu mekanisme transfer mulai dari pemindahan energi, paans sampai dengan momentum. Pemindaan energi adalah perjalanan radiasi matahari dari sumbernya sampai ke permukaan bumi kemudian memanasi atmosfer, permukaan tanah dan udara. Perpindahan panas terjadi secara konduksi dan konvektif. Kemudian, pemindahan momentum yang memungkinkan angin membawa muatan mulai dari air, $\mathrm{CO}_{2}, \mathrm{O}_{2}$, methane dan unsur lainnya dengan kecepatan yang dikendalikan daya dorong akibat perbedaan tekanan dan konsentrasi massa serta diganggu oleh permukaan sentuhan sehingga berlangsung secara laminer dan turbulen.

Salah satu parameter atmosfer tambahan yang dapat relevan dalam kajian iklim mikro adalah kondisi stabilitas atmosfer. Bilangan Richardson yang diturunkan dari gradien suhu dan kecepatan angin dapat digunakan untuk menentukan selang inversi di atmosfer. stabilitas atmosfer dapat berperan dalam penyebaran spora patogen dan perilaku terbang serangga dalam skala harian dan musiman (Richardson, 1922 dalam Hatfield, 2012).

Kabupaten Konawe Selatan dikenal sebagai sentra produksi beras karena didukung oleh aspek luas lahan pertanian sawah untuk budidaya padi dan aspek sumber daya pertanian yang potensial dalam mengembangkan sub sektor pertanian tanaman pangan padi. Rata-rata setiap tahun Kabupaten Konawe Selatan mampu menghasilkan 1,5 juta ton Gabah Kering Giling atau setara dengan 1 juta ton beras siap konsumsi (Dinas Pertanian Kab. Konawe Selatan, Tahun 2015). Oleh karena itu penelitian terkait stabilitas atmosfer dalam iklim mikro dianggap penting untuk menunjang pertanian di Konawe Selatan.

Penelitian terkait analisis bilangan Richardson telah dilakukan oleh Alisawati (2019) dalam Sosaidi, dkk, (2020) yang melakukan penelitian di Banjarbaru Kalimatan Selatan, mendapatkan korelasi antara Bilangan Richardson (Ri) dengan transfer bahang dan momentum pada periode JJA (Juni, Juli, Agustus 2019) mendapatkan nilai korelasi (r) antara 0.41 hingga 0.68 pada ketinggian 4 meter.

Di sisi lain transfer bahang dan momentum sangat berkaitan dengan stabilitas atmosfer. Hal tersebut diteliti oleh Haidar (2019) dalam Sosaidi, dkk, (2020) pada penelitiannya di Tangerang Selatan, menghitung kondisi stabilitas permukaan dengan nilai Ri sebelum kejadian hujan cenderung negatif, sedangkan saat hujan Ri positif, dan setelah kejadian hujan Ri cenderung nol (0). Penelitian yang mengkaji stabilitas mikro atau stabilitas udara hubungannya dengan hujan dan juga proses fisis di atmosfer yaitu proses konvektivitas dalam lingkup mikro di Stasiun Klimatologi Kelas I Bogor telah dilakukan oleh Sosaidi, dkk, (2020) yang mendapatkan hasil bahwa proses iklim mikro dapat menggambarkan proses konveksi.

\section{METODE PENELITIAN}

Data

Data yang digunakan dalam penelitian ini yaitu data iklim mikro (suhu dan kecepatan angin) dengan ketinggian 2, 4 dan 7 meter yang diamati pada jam 07.00, 13.00, dan 18.00 WITA menggunakan alat iklim mikro otomatis dan data curah hujan harian yang diamati pada jam 07.00 WITA menggunakan lat penakar hujan OBS selama bulan Maret 2021 yang bersumber dari Stasiun Klimatologi Konawe Selatan. Dari 31 hari dalam bulan Maret 2021, terdapat 6 hari missing data pada data yang penulis dapatkan yaitu pada tanggal 17-22 Maret 2021. Sehingga data yang digunakan dalam tulisan ini sebanyak 25 hari pada Maret 2021.

\section{Metode}

Curah hujan konveksional disebabkan oleh konveksi bebas akibat pemanasan, proses dinamik seperti konvergensi atau pemaksaan fisis di atas pegunungan (Wiryohamijoyo.S \& Swarinoto.Y.S, 2013). Curah hujan konveksional bisa terjadi dalam ruang $10-20 \mathrm{~km}$ persegi. Untuk hujan orografik disebabkan oleh kondensasi dan pembentukan awan udara lembab yang dipaksa naik oleh gunung atau barisan pegunungan. Jadi hujan orografik dapat dikategorikan sebagai adanya konveksi paksa.

Tingkat pendinginan permukaan yang berbeda dapat terjadi karena perbedaan stabilitas atmosfer. Dalam studi ini gradien bilangan Richardson (Ri) digunakan untuk menilai dampak stabilitas pada tingkat pendinginan permukaan. Gradien bilangan Richardson mewakili kontribusi relatif dari daya apung dan geser angin untuk produksi/penghancuran turbulensi (Stull, 1988). 


$$
R i=\frac{g}{T a} \frac{\left(\frac{\partial \theta}{\partial \mathrm{z}}\right)}{\left(\frac{\partial \mathrm{u}}{\partial \mathrm{z}}\right)^{2}}
$$

\section{Keterangan:}

$\mathrm{g}$ : Kecepatan gravitasi $\left(\mathrm{m} / \mathrm{s}^{2}\right)$

$\theta$ : Suhu potensial $(\mathrm{K})$

Ta: Suhu absolut pada ketinggian $\mathrm{za}: \mathrm{za}=\left(\mathrm{z}_{1} \mathrm{z}_{2}\right)^{1 / 2}$

$\mathrm{u}$ : Kecepatan angin $(\mathrm{m} / \mathrm{s})$

z: Tinggi Pengukuran (m)

Suhu potensial lingkungan dapat di cari dengan menggunakan persamaan sebagai berikut (Oke, 1988):

$$
\theta=T-(\Gamma \mathrm{d} . z)
$$

\section{Keterangan :}

$\mathrm{T}$ : Suhu Lingkungan $(\mathrm{K})$

$\Gamma \mathrm{d}$ : Dry Adiabatic Lapse Rate atau penurunan suhu pada adiabatik kering $=-0.00976 \mathrm{~K} / \mathrm{m}$

$\mathrm{z}$ : Tinggi Pengukuran (m)

Kecepatan angin rata-rata pada ketinggian $\mathrm{z}$ diperoleh melalui persamaan sebagai berikut:

\section{Keterangan :}

$$
\frac{u(z)}{u^{*}}=\frac{1}{k} \ln \frac{(z-d)}{z_{0}}
$$

$\mathrm{u}(\mathrm{z})$ : kecepatan angin rata-rata pada ketinggian $\mathrm{z}(\mathrm{m} /$ detik $)$

$\mathrm{u}^{*}$ : kecepatan kasap (m/detik)

$\mathrm{k}$ : konstanta Von Karman 0.4

zo : panjang kekasapan $(\mathrm{m})$

$\mathrm{d}:$ perpindahan bidang nol $(\mathrm{m})$

Pada umumnya kecepatan angin rata-rata $\mathrm{u}(\mathrm{z})$ naik secara linier terhadap $\ln (\mathrm{z}-\mathrm{d})$. Nilai $\mathrm{d}$ ini berkisar antara 0.6 sampai $0.8 \mathrm{~h}$ ( $\mathrm{h}=$ tinggi unsur kekasapan). Nilai d dapat diduga dengan persamaan berikut (Oke, 1978; Suciatiningsih, 2013, Haidar, 2019):

$$
d=\frac{2}{3} h
$$

dimana $\mathrm{h}$ merupakan tinggi rata-rata permukaan $(\mathrm{m})$. Untuk $\mathrm{h}$ di Stasiun Klimatologi Konawe Selatan diasumsikan 4 meter.

Nilai parameter $\mathrm{z}_{0}$ ditentukan dengan mengekstrapolasi hubungan linier antara $\mathrm{u}(\mathrm{z})$ dan $\ln (\mathrm{z}-\mathrm{d})=\mathrm{z}_{0}(\mathrm{y}$ $\left.=\ln \mathrm{z}_{0}\right)$, dan menghasilkan slope $=\mathrm{k} / \mathrm{u}^{*}$.

Menurut Oke (1988), nilai $\mathrm{z}_{0}$ dapat ditentukan dengan persamaan sebagai berikut:

$$
\log z_{0}=\log h-0,98
$$

Karakteristik nilai parameter $\mathrm{z}_{0}$ dan $\mathrm{d}$ berubah-ubah secara sistematis mengikuti perubahan angin. Pada beberapa permukaan, nilai $\mathrm{z}_{0}$ turun seiring dengan menurunnya keceatan angin dan $\mathrm{d}$ hampir konstan. Namun diatas permukaan yang lain, $\mathrm{z}_{0}$ naik dengan meningkatnya kecepatan angin dan $\mathrm{d}$ turun.

Nilai positif yang besar dari Ri sesuai dengan kondisi stabil dengan pencampuran turbulen yang lemah.

Tabel 1. Kriteria Untuk Kestabilan Atmosfer (Stull, 1988)

\begin{tabular}{lcl}
\hline Kondisi & Kriteria & Klasifikasi Atmosfer \\
\hline 1 & $\mathrm{Ri}=0$ & Netral \\
& $\mathrm{Ri}<0$ & Unstabil \\
& $\mathrm{Ri}>0$ & Stabil \\
2 & $\mathrm{Ri}<-0.03$ & Konveksi bebas \\
& $\mathrm{Ri}>-0.03$ & Konveksi paksa \\
& $\mathrm{Ri}>0.25$ & Stabil \\
& $\mathrm{Ri}=0$ & Netral \\
\hline
\end{tabular}




\section{HASIL DAN PEMBAHASAN}

Dalam penelitian ini, kriteria kestabilan atmosfer dibagi menjadi 2 kondisi menurut stull (1988). Kondisi 1 digunakan untuk menggambarkan kestabilan atmosfer pada klasifikasi netral, unstabil, dan stabil untuk seluruh data penelitian selama 25 hari. Kondisi 2 digunakan untuk menggambarkan kestabilan atmosfer pada klasifikasi Konveksi bebas, konveksi paksa, stabil, dan netral untuk data penelitian yang dibagi menurut kategori hari hujan dan hari tanpa hujan.

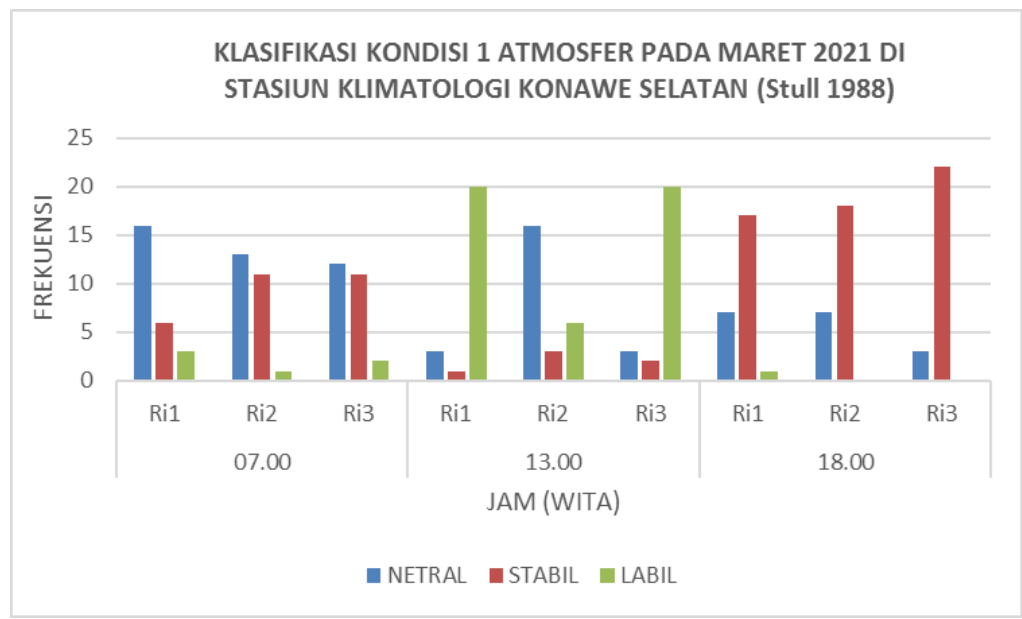

Gambar 1. Klasifikasi kondisi 1 atmosfer pada seluruh data

Berdasarkan Gambar 1 di atas, dapat dilihat klasifikasi kondisi 1 atmosfer pada bulan Maret 2021 di Stasiun Klimatologi Konawe Selatan. Pengamatan kondisi atmosfer dilakukan pada 3 keadaan yaitu, Ri1 menggambarkan kondisi atmosfer iklim mikro pada ketinggian 2-4 meter, Ri2 menggambarkan kondisi atmosfer pada ketinggian 4-7 meter, dan Ri3 menggambarkan kondisi atmosfer pada ketinggian 2-7 meter.

Pada Gambar tersebut terlihat bahwa pada jam pagi hari kondisi atmosfer didominasi pada keadaan atmosfer netral. Hal ini disebabkan karena pada pagi hari intensitas penyinaran matahari masih sedikit. Kondisi serupa juga dapat dilihat pada kondisi atmosfer pada sore hari, dimana kondisi atmosfer pada sore hari juga didominasi klasifikasi atmosfer stabil. Kondisi stabil umumnya terjadi saat hujan dengan intesitas ringan atau setelah hujan. Sedangkan kondisi atmosfer pada siang hari didominasi oleh klasifikasi atmosfer labil.

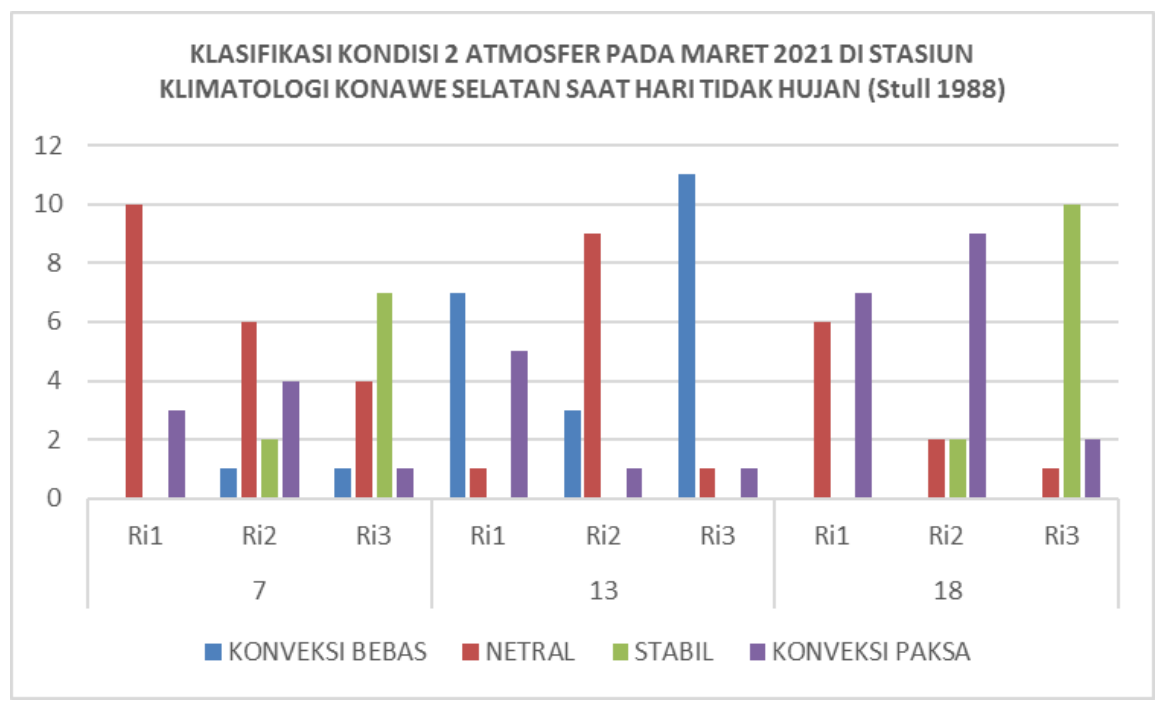

Gambar 2. Klasifikasi kondisi 2 atmosfer pada saat hari tidak hujan

Pada Gambar 2 di atas dapat dilihat kondisi 2 atmosfer pada saat hari tidak hujan. Terlihat pada pagi hari klasifikasi atmosfer didominasi oleh kondisi netral. Sedangkan pada saat siang hari kondisi atmosfer didominasi oleh klasifikasi konveksi bebas. Serta saat sore hari didominasi oleh klasifikasi konveksi paksa dan stabil. 


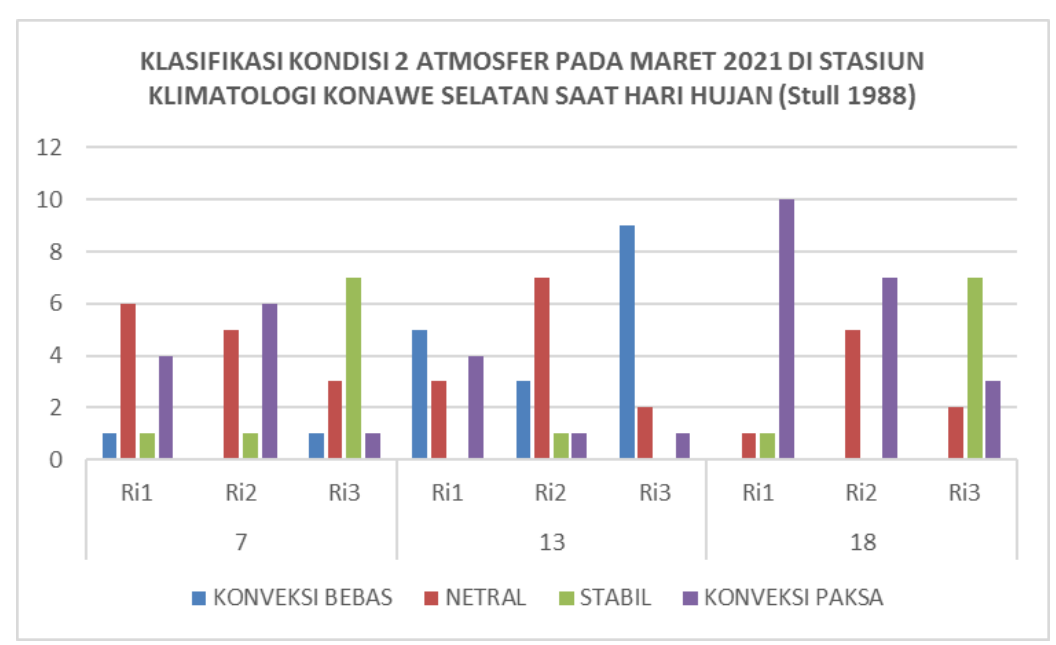

Gambar 3. Klasifikasi kondisi 2 atmosfer pada saat hari hujan

Kondisi 2 atmosfer yang menggambarkan klasifikasi atmosfer konveksi bebas, netral, stabil, dan konveksi paksa pada saat hujan tertera pada Gambar 3. Dapat dilihat bahwa pada saat pagi hari, kondisi atmosfer didominasi oleh klasifikasi netral. Sedangkan pada siang hari didominasi oleh klasifikasi konveksi bebas. Dengan kejadian yang didominasi adanya konveksi bebas ini, dapat menggambarkan bahwa faktor angin yang masih dominan adalah angin regional atau musiman seperti monsoon barat, mengingat saat penelitian ini adalah periode Maret 2021 di Stasiun Klimatologi Konawe Selatan dan sekitarnya masih mengalami musim hujan. Sedangkan, saat sore hari kondisi atmosfer di wilayah pengamatan didominasi oleh konveksi paksa.

Tingginya klasifikasi konveksi paksa pada saat sore hari untuk kondisi saat hari hujan dan hari tidak hujan dapat menunjukkan bahwa terdapat hujan orografik yang terjadi karena konveksi paksa dari pegunungan. Hal ini didukung dengan wilayah pengamatan, yaitu Stasiun Klimatologi Konawe Selatan yang dekat dengan wilayah perbukitan dan Pegunungan Boroboro.

\section{KESIMPULAN}

Berdasarkan hasil dan pembahasan pada penelitian ini, maka dapat disimpulkan sebagai berikut:

a. Kestabilan kondisi atmosfer di lokasi pengamatan dapat dideteksi proses mikronya yang dapat menggambarkan proses konveksi.

b. Berdasarkan pengamatan pada Kondisi 1 atmosfer terlihat pada pagi hari didominasi kondisi netral, siang hari labil, dan sore hari stabil.

c. Pada kondisi 2 atmosfer pada saat hari tidak hujan dan saat hari hujan pada saat pagi hari didominasi oleh kondisi netral, siang hari konveksi bebas, dan malam hari konveksi paksa.

d. Konveksi bebas menggambarkan bahwa angina di wilayah pengamatan masih didominasi oleh angin muson dan masih masuk ke dalam musim hujan. Serta, konveksi paksa menggambarkan bahwa terdapat hujan orografik, hal ini didukung dengan topografi wilayah pengamatan yang dekat dengan perbukitan dan Pegunungan Boroboro.

\section{DAFTAR PUSTAKA}

Alisawati, R. K, 2019. Kajian Stabilitas Atmosfer Permukaan dan Pengaruhnya Terhadap Laju Transfer Momentum Pada Saat Kejadian Kabut di Wilayah Banjarbaru Pada Tahun 2018. Skripsi. Sekolah Tinggi Meteorologi Klimatologi Dan Geofisika.

Dinas Pertanian dan Peternakan Provinsi Sulawesi Tenggara, Tahun 2015.

Dinas Pertanian Kabupaten Konawe Selatan Tahun 2015.

Haidar, T.N. 2019. Kajian Laju Transfer Momentum Terhadap Kondisi Stabilitas Udara permukaan sebelum Saat Dan setelah Hujan Di Kota Tangerang Selatan. Skripsi. Sekolah Tinggi Meteorologi Klimatologi Dan Geofisika.

Hatfield, J. (Ed.). (2012). Biometeorology in integrated pest management. Elsevier.

Jones, M. B. (1985). Plant microclimate. In Techniques in bioproductivity and photosynthesis (pp. 26-40). Pergamon.

Oke, T.R. 1978. Boundary Layer Climates. London: Methuen \& Co Ltd. 
Sosiadi, D., dkk. 2020. Analisis Bilangan Richardson (Ri) Untuk Stabilitas Atmosfer Meteorologi Mikro Di Staklim Bogor. Jurnal Saintika Unpam. Volume 2 No. 2.

Stull, R. B. (1988). An introduction to boundary layer meteorology. (Vol. 13). Springer Science \& Business Media.

Suciatiningsih. F. 2013. Karakteristik Kekasapan Permukaan Dan Pengaruhnya Terhadap Transfer Turbulen Momentum Dan Bahang. Skripsi. Departemen Geofisika Dan Meteorologi Fakultas Matematika Dan Ilmu Pengetahuan Alam Institut Pertanian Bogor.

Wiryohamijoyo,S dan Swarinoto, Y.S. 2013. Meteorologi Sinoptik: Analisis dan Penaksiran Cuaca Sinoptik. Pusat Penelitian dan Pengembangan Badan Meteorologi Klimatologi dan geofisika, Jakarta. 